\title{
THE DYNAMICS OF ESTABLISHING ORGANIZATIONAL WEB SITES: SOME PUZZLING FINDINGS
}

\author{
Celia T. Romm \& Jeanne Wong \\ University of Wollongong \\ Department of Business Systerms \\ Wollongong. NSW, 2522, Australia \\ Telephone No: +61242214043 \\ Fax No: +61242214474 \\ Email: Celia_Romm@uow.edu.au \\ Email: Jeanne_Wong@uow.edu.au
}

\begin{abstract}
A survey of the currently available literature on diffusion of Web technologies reveals that it is at a very early stage of development. As a result, it is difficult, if not impossible, to use existing models to describe or explain the process of establishing organizational Web sites. One of the few theoretical models that can be used as a starting point for research in this area is the Jarvenpaa and Ives (1996) model. The model consists of five propositions that describe what the authors see as the essential aspects of the diffusion of Web technology. The purpose of this paper is to compare data collected in an Australian university to the propositions of the Jarvenpaa and Ives model. The comparison demonstrates that there is a need for a more generic model which would explain the diffusion process of Web technologies in diverse organizational and cultural contexts. The paper is concluded with a discussion of the political, industrial, and cultural reasons that may explain the differences between the dynamics in our case and those described in the Jarvenpaa and Ives model.
\end{abstract}

\section{Keywords}

Web Technologies, Web Sites, Electronic Commerce, Virtual Communities, Organizational Transformation, Organizational Strategy, Australian Case

\section{INTRODUCTION}

Recent publications herald Web technology as a revolutionary or transformational technology, i.e., one with the potential to dramatically change the way that organizations conduct their business (Bickel 1996; Kalakota \& Whinston 1996; Rayport \& Sviokla 1995). Some of the areas that are seen as most likely to undergo radical change as a result of the introduction of Web technologies to business organizations are: (1) informational structures; (2) management strategies; (3) distribution channels; and (4) product mix.

A survey of the literature on Web technologies reveals that even though it is growing at a high rate, much of it is still dedicated to the technical aspects of the diffusion process such as how to connect to the Internet (LeJeune \& Duntemann 1995) and how to use Web browsers such as Mosaic, Netscape and Microsoft Internet Explorer (Brown et al 1995; Krol 1994; Pitter \& Minato 1996). Other areas within the growing body of research on Web technologies include the study of marketing implications of the Web (Savola, Westenbroek \& Heck 1995), and design issues (Emery 1996; Sterne 1995).

Most importantly for our purposes, there is only a handful of studies that actually describe the process of diffusion of organizational Web technology within organizations. One of the pioneering studies in this area was recently conducted by Jarvenpaa and Ives (1996). In their research, the authors did not only describe in detail how two organizations in the US developed their Web technology capabilities, but also made a series of propositions on how this process can be theoretically conceptualized.

The objective of this paper is to use the Jarvenpaa and Ives (1996) study as a starting point for a more general model capable of describing the diffusion of Web technologies in organizations. To achieve this goal, this paper goes through the following steps. First, based on the Jarvenpaa and Ives (1996) model, five propositions that have been identified by these authors as relevant to the diffusion of Web technologies in organizations are outlined. Second, based on data collected in Australia, the degree to which the Jarvenpaa and Ives' propositions can be generalized across industries and cultures is assessed. Third, given that there is a gap between the Jarvenpaa and Ives' propositions and the Australian case, an alternative approach, the Establishing Organizational Web Sites (EOWS) model, is presented. The paper is concluded with a discussion of directions for future research and methodological implications from the EOWS model.

\section{LITERATURE REVIEW}

Before we consider the Jarvenpaa and Ives (1996) paper, a few words about the diffusion of information technology innovation in general are in order. McFarlan and McKenney (1982) were among the first to suggest that during the diffusion of new information technologies, the creative functions of implementation should be 
separated from the control functions. Furthermore, they suggested that organizational structures should be modified to support the different aspects of the diffusion process. Thus, while a more flexible, organic structure where management controls are loose and informal was recommended for the earlier, more creative stages of technology diffusion, a rigid, mechanistic organizational structures and procedures were seen as appropriate for the later, more control stages of the diffusion process.

Following the McFarlan and McKenney directive, Cash, McFarlan and McKenney (1983) advocated the creation of special groups within the information technology function or appointing special "idea champions" as intermediaries between users and information technology. These individuals or special groups were expected to identify new technologies that had the potential to address users' needs, and, then, support the development and diffusion of such technologies within the organization. Cash and McLeod (1985) suggested in another paper that strategic planning processes led by top management might help identify promising technologies and then provide funds for piloting them in the organization prior to an organizational-wide implementation.

In contrast to these directives, other researchers, most particularly those borrowing models from the literature on organizational radical change (Gersick 1991; Beers, Eisenstat \& Spector 1990) maintained that the diffusion of informational technologies that are "revolutionary" in nature, cannot be initiated by the upholders of the status quo. These theorists claimed that there are cognitive, motivational and organizational reasons why those who are in positions of power would be unable to lead changes that undermine revolutionary change, instead, they advocated the importance of "idea champions" (Schon 1963; Howell \& Higgins 1990) as vehicle of spontaneous, non-organizationally sanctioned innovation and change.

A variety of issues were mentioned by researchers as reasons for the fact that radical change cannot be led by those in power. These included:-

(1) People's past experience and education dictate the alternatives that they consider. People in position of power are constrained by their personal experiences. Given that these people are often older than the idea champion of new technologies, they might be less inclined to support them (Dearborn \& Simon 1958).

(2) Revolutionary change involves a loss of what is familiar and comfortable. Given the fact that radical change may influence the distribution of power within an organization, elevating the change champions at the expense of others, it may be resented by those likely to lose power, namely, those in current positions of power (Markus 1981 \& 1983).

(3) Current organizational policies and obligations constrain the behaviour of current stakeholders. Another way of stating this argument is to argue that as individuals and groups become more skilled in their activities, they have a tendency to routinize their modes of behaviour and become less inclined to change them (March \& Simon 1958).

The obvious conflict between the above arguments in that some of them advocate top management involvement as a pre-requisite to a project success, while others, claim that radical change cannot be led by top management, was the theoretical starting point for the Jarvenpaa and Ives (1996) study, which is one of the pioneering attempts to systematically analyze the process of Web technologies diffusion in organizations.

Based on two in-depth case studies conducted in two computer companies in the US, Jarvenpaa and Ives made five propositions that reflect their understanding of what the diffusion of Web technologies in organizations is about.

The first proposition in the Jarvenpaa and Ives model is that the introduction of Web technologies is likely to occur with only peripheral involvement of the information technology function. This assertion was supported by the fact that in both organizations studied by the authors members of the informational technology unit were either peripherally involved or took a traditional control orientation which centered around formalizing, and safeguarding the existing information systems resource.

The second proposition in the Jarvenpaa and Ives model is that the introduction of Web technologies is likely to occur with minimal if any involvement by top management. This assertion was supported by the fact that in both organizations studied by the authors top management was very minimally involved, particularly at the early stages of the diffusion process. In both organizations Web technology was diffused for months and used extensively by a large number of organizational members before members of top management (in both cases the company CEO) expressed support for the project publicly.

The third proposition in the Jarvenpaa and Ives model is that the introduction of Web technologies is likely to be accomplished by an ad-hoc, cross-functional group that has no formal organizational responsibility for promoting the technologies. This assertion was supported by the fact that in both organizations studied by the authors ad hoc groups, mostly from the R\&D and marketing Communication areas were established as informal champions of Web technology. In both cases, these groups invested significant efforts in demonstrating the profit potential of the new technologies, giving presentations to external CIO's, and fostering attention from the external press to the importance of Web technologies. 
The fourth proposition in the Jarvenpaa and Ives model is that a performance crisis can be used to stimulate the introduction of Web technologies to an organization, but that a crisis is not necessary for this change to occur. The assertion was supported by the fact that one of the two organizations studied by the authors experienced a performance crisis shortly after the Web technologies project had started. It was thanks to this crisis that the CEO and other top managers began to see Web technologies as part of a solution that can benefit the company.

The fifth proposition in the Jarvenpaa and Ives model is that the introduction of Web technologies to an organization can be triggered or supported by "staged events", some of which could be deliberately manufactured" by the leaders of the project. This assertion was supported by the data collected by the authors in that in both organizations, the project leaders took advantage of real or imagined deadlines to push the project forward. While in one organization the deadlines were largely "manufactured" by the leaders, in the other they were triggered by a real threat from the competition when it was revealed that it was about to launch its own Web page.

In the following sections the above propositions are considered as they apply to case data collected in Australia. The discussion attempts to reconcile the differences between the American and the Australian experience by proposing the EOWS model.

\section{CASE STUDY}

\section{Methodology}

Data for this study were collected by the authors at an Australian university referred to here as UOA (the name of the University as well as the names of all characters in the case have been withheld to protect their anonymity the names that are used are pseudonyms). Data was collected over a period of two years.

The major source of data for this study were interviews which were conducted with twenty members of the University. An additional source of information were a variety of hard copy documents supplied to the researchers by the interviewees. During data analysis, data from all sources pertinent to a particular event were analyzed and the interpretations of all interviewees for that event compared. A decision as to the meaning of the event for the various individuals involved was reached only when it was supported by the data from all sources and when it was agreed on by the researchers.

\section{Interviews:}

In-depth interviews with twenty members of UOA were the most important source of data for this study. During data collection, a semi-structured interview schedule, consisting of a series of open ended topics was utilized. The questions gauged interviewees' memory of the events, as well as their interpretation of the events' meaning. Even though the interview schedule was semi-structured, an attempt was made to cover the same topics in all interviews. Issues on which interviewees disagreed received special attention. When such issues were identified, they were included in subsequent interviews, with special attempt made to reach consensus among the interviewees over these issues. In addition to gathering personal details (such as background information, career data, and future plans), interviewees were asked to describe the quality of their work life while the case events took place, relationships with other members of the organization, and areas of responsibility. The interviews lasted on average about ninety minutes, and were all taped, transcribed and analyzed by the authors.

A content analysis scheme was used for the interview data. The scheme included a categorization of major themes in the interviews, with particular emphasis on issues relating to the details of the implementation events and the interpretation of these events by the interviewees.

Interviews were conducted over a period of two years (1995 to 1996), which roughly corresponded to the duration of the case events. On average, two interviews were held with each interviewee, bringing the number of interviews to forty. Members of three major groups were interviewed:-

(1) Academic Staff - There were 10 interviewees from the academic staff; four Professors (including two Department Chairs and one Dean); three Associate Professors; and three Assistant Professors. The academic sample was derived from six different departments from all major divisions at UOA. All academics selected as interviewees had direct or indirect knowledge of the events on which the case focused. To make sure that information about the case events was as complete as possible, all members of the University Campus Wide Information Systems (CWIS) committee (see following sections for more details) were interviewed.

(2) Administrative Staff - Five interviews were conducted with individuals who were categorized as "administrative staff". From top management, the Provost and the Personal Assistant to the President were interviewed. Two secretaries were also interviewed. Each of the secretaries was from a different department within UOA strongly associated with the Web technology project. 
(3) Five interviewees were members of the Information Technology Department (ITD): the Head of the Department, the Head of User Services, the secretary of the CWIS committee and the past and present co-ordinators of the Web project support unit were interviewed.

\section{Textual analysis:}

A variety of documents were collected at various stages of the implementation project. These included promotional materials, training transparencies, and minutes of relevant meetings. Textual analysis also included in-depth study of the organizational chart, hard and soft copy correspondence, newspaper clippings, and progress reports. A major source of data for the textual analysis was e-mail messages. Over 100 e-mail messages pertaining to the project were made available to the author by the key players in the case. The e-mail messages were analyzed using a specially constructed qualitative content analysis scheme. The scheme involved a thematic categorization of the issues discussed on e-mail by the various players in the case.

\section{Case Data}

UOA is a medium- sized university, with over 1000 staff members and over 13,000 students. The university is centrally located within a densely populated, highly industrialized metropolitan area. UOA has a reputation for being one of the most technologically advanced academic institutions in the country, investing substantial resources in experimental emerging technologies. The diffusion of Web technologies at UOA followed a highly successful e-mail implementation, which started in 1988 and was completed in 1992, shortly before the case events started. In the following sections we will describe the diffusion of Web technologies at UOA in terms of four phases, spanning the years 1993-1996.

\section{(1993) - Sporadic Diffusion of Web Technologies:-}

Following the success of the e-mail diffusion in the years prior to 1993, many staff members at UOA were using early Internet technology during 1992 and 1993. The majority of users were academics. They were using a variety of search engines such Mosaic, Archie and Gopher, to support their research and networking initiatives with colleagues in other academic institutions.

In mid 1993, the Head of the Information Technology Unit (TTU), Mr. Adam Neil, was becoming aware of the need to identify one UNIX based, multi-platform (compatible with both Mac's and PC's) to support the file servers around the university. In the search for the one technology that would be best suited for UOA, Mr. Neil instructed his subordinates to consider and test several options, including, Gopher, WAIS, Apple Share and Mandarin. Despite the search effort, by the end of 1993, a decision as to the best technology to support Internet servers on campus had not been made.

\section{(1994) - The CWIS Committee:-}

The first months of 1994 marked a dramatic change in the development of the Web technologies project. The change started when Professor Mark Lind, UOA Provost for Research and the Chair of UOA Computer Planning Policy committee (CPPC), announced during the committee's first meeting for the year that the President of UOA had authorized him to suggest to the committee the launching of a Campus Wide Information Systems (CWIS) project. A CWIS steering committee was to be created as a sub-committee of the CPPC. The CWIS committee was to supervise a project that would result in the creation of an integrative multi-platform Web based intranet for UOA. By the end of the meeting, the Computer Planning committee has appointed Mr. Anthony Moore, one of Mr. Neil's deputies and the Head of the Administration Information System (AIS) unit, as Chair of the newly established CWIS committee.

Following the decision of the CPPC, Mr. Neil has instructed a team of experts within ITU to renew the search for a technology that could support Internet servers around the campus. By this time (mid 1994), Web technologies have become popular in the industry. They were seen by the members of the ITU search team as much more exciting than the options that they considered in 1993. Most importantly, Web technologies were seen as the most appropriate solution to UOA's multi-platform problem. Following this line of reasoning, the group decided to recommend the Web as the anchor for the University information infrastructure. In line with this recommendation, contact was established with several Web technologies vendors. Within a few weeks, a contract was signed with Netscape. Within a few more months Netscape Enterprise, the company's more advanced product with more features to support an intranet was adopted as the UOA Web technologies infrastructure.

By the end of 1994 the newly established CWIS committee held its first meeting. The meeting was attended by five individuals. Three of the committee members were from ITU (including Mr. Neil and Mr. Moore). The 
remaining two members included Mr. Jack Ford, the Head of UOA Department of External Relations, and Professor Jeffrey Wood, Chair of the Department of MIS. The major decision made by the committee during its first meeting was to allocate $\$ 40,000$ as a salary to a person appointed as co-ordinator of the Web technologies project. The money was to be allocated in equal shares by ITU and the University central administration. It was agreed the person hired as co-ordinator of the Web technologies project would also be the secretary of the CWIS committee.

Within a month after the committee's meeting took place, Mr. James Cooper took office as the new co-ordinator of the Web technologies project. Mr. Cooper had an extensive experience as a manager in the IS industry. He has been working with Web technologies for years, including several years experience as a private consultant in this area. By appointing him as co-ordinator of the project, the members of the CWIS committee have clearly expressed a commitment to Web technologies.

\section{(1995) - Launching the Web Project:-}

Mr. Cooper's appointment marked the formal start of the Web technologies project. Mr. Cooper interpreted his role as co-ordinator of the project in several ways. First, as secretary of the CWIS committee, he decided to make the committee more representative of the University community. To achieve this goal he decided to approach three additional academics and invite them to join the committee. The new members included Professor Jane Peel, the Chair of Computer Science, Professor Susan Brown, the Chair of Ar History, and Professor Gill Grant, Chair of Psychology. The addition of the three professors did not only change the committee in terms of disciplinary representation (with less representation to IT people and more to members of other units within the University), but also made the committee significantly more balanced in terms of gender.

Another decision taken by Mr. Cooper was to focus the committee's work around the establishment of a new Web site. Even though the University already had a one page Web site, it was felt that a much more sophisticated site was needed. During the remaining of 1995 , discussions over the content of the Web site became the main issues of concern for the CWIS committee. The debates focused on the following issues:-

(1) the design question: while the administrative members of staff on the committee were adamant that the first page of the Web site should highlight issues relating to Foreign Students, who represented a major source of income for the University, the academic insisted that such a design would be discriminatory to other sub-group within the student body, i.e., blacks and females. It was finally resolved that all students would appear on the top of the list as one group.

(2) the standards issue: while the representative of the IT group and the External Affairs group within the committee were strong advocates of one set of standards, the academic members of the committee saw the attempt to impose such standards as "stifling of academic creativity". After long debates, it was finally agreed that the various departments within the University will be allowed to use whatever design tools, color scheme, or structure they chose. The only proviso was that all departments will put the University logo at the bottom of their "official" Web pages.

(3) the control debate: here the committee was divided between the more technically oriented members who felt that the ultimate control of the Web site should be with ITU, and the academic members of the committee who felt that departments should not be pestered by the IT group when to update their Web pages. The final decision of the committee was that ITU will make its expertise available to departments who will choose to approach it for training and advice. However, it will not police that the Web site and will not impose deadlines on the update of individual Web pages.

By the end of 1995 the CWIS committee has met four more times (bringing the total number of meetings for that year to five). Toward the end of the year, the format for the University Web site (the first page) was agreed on. Mr. Cooper was instructed to construct individual pages for the different units within the University. In particular, he was to lead the very difficult and time consuming project of getting most of central administration documents on the Web - a project that was expected to continue for at least another year.

\section{(1996) - Consolidation of the Web Project:-}

The CWIS committee continued to hold meetings during 1996 but not at the same frequency as during 1995 . During the year only two meetings were held and these were attended by less than two thirds of the members of the committee.

During 1996 several members of the committee started to be disillusioned with the project. During the CWIS committee meetings, several of the academic members complained that the promise to create a "paper free organization" was not forthcoming. Indeed, many of the central administration departments who were supposed 
to convert their hard copy documents to electronic databases and make them available to users on the University's Web server, did not meet this goal, claiming that other responsibilities left them no time to perform this extra job. Other members of the committee appeared to be concerned about issues of data security. Thus, several of the academic members of the committee who were initially enthusiastic about the prospect of using the Web to send thesis to external referees, started to worry that the Web was not secure enough for this purpose. Other members of the committee raised concerns about access to University databases by unauthorized personnel, most specifically, students.

By the end of 1996, Mr. Cooper, the project co-ordinator, was starting to realize that many departments within the University were simply not joining the Web technology bandwagon. Despite pressures from ITU, and continuing investment in training and promotion efforts, it was clear that the project was not going to be completed by the end of 1996 as was expected by the members of the CWIS committee. This prompted Mr. Cooper to ask for additional resources that would allow him to establish a special development group to assist units that were unable to meet the deadline. The proposal did not win the support of the majority of the CWIS committee members, many of whom claimed that the project leaders should concentrate on the "quality" of the University Web site rather than on its "quantity". The unanimous decision of the committee, was, however, that if Mr. Cooper felt that additional resources were necessary, he should attempt to secure them through his superiors at the ITU.

Five months later, when 1996 drew to a close, Mr. Cooper finally managed to secure the necessary resources to finish the project. By this time, the majority of the departments at UOA, had their own Web pages and so the money was to be invested in development of Web based databases to support the Administration services on the Web server.

Interestingly, and despite the technical success of the Web technologies project the views of the UOA members about it were highly polarized. While many academics, (including the academic members of the CWIS committee) said that they were manipulated by the IT group into being a rubber stamp to IT's secret agenda, the IT people (including the IT members of the committee) blamed the "academics" for what they saw as "the less than optimal outcome of the project".

\section{DISCUSSION}

What can we learn from the data in the case study? Despite the fact that the case study took place in a University, an organization with a unique culture that differs significantly from other industries, the differences between our findings and those of the Jarvenpaa and Ives' (1996) study are striking. In contrast to the propositions of the Jarvenpaa and Ives model, in UOA, the Web technologies project was very much led by the information technology unit, with high degree of involvement by top management. Furthermore, in our case study, the Web technology project was not triggered by a performance crisis, nor was it punctuated by event based crises manufactured by the project team.

Put differently, it appears that the Australian case lacked almost all the characteristics that led Jarvenpaa and Ives to label the Web technologies project in their sample "transformational", "radical" or "revolutionary". In our case, the project was a reflection of the continuing commitment of UOA's top management to technological innovation. It was also a natural continuation of other projects initiated by the IT function prior to the case events. In view of the fact that both the IT group and other members of top management were directly involved in the project right from the start, it is difficult to claim that it posed a threat to the organizational power distribution or changed it in a significant way as suggested by the label of "transformational", "radical", or revolutionary.

How can we explain the disparity between the Jarvenpaa and Ives propositions and our case? Several answers can be given to this question, each pointing at a different direction for an extension of the Jarvenpaa and Ives framework.

The first possible explanation relates to the fact that the data for the Jarvenpaa case studies was collected in organizations which represented a different industry than the Australian case. The Jarvenpaa and Ives' case studies were based on data collected in two computer companies, while the Australian case centered around the diffusion of Web technologies in a university. It can be argued that the two industries differ not only in their organizational structure and work processes, but, more importantly, in their organizational culture, leading to totally different strategies of diffusing Web technologies. This possibility calls for an integration of the variable of "industry" in any model that attempts to theoretically conceptualize the process of establishing organizational web sites.

Another possible explanation for the disparity between the Australian case and the Jarvenpaa and Ives findings might be related to the fact that the data for the Jarvenpaa and Ives study was collected in the US, while the data for our case was collected in Australia. Prior research on national cultures (Hofstede 1980, 1994a; and 1994b) tells us that national culture is a major variable determining relationships within organizations. Even though the American and Australian cultures are assumed by Hofstede to be quite similar, some significant differences 
between them do exist. In particular, the Australian culture is significantly higher than the American culture on uncertainty avoidance (Australians are more risk avert). The Australian culture is also significantly lower on power distance (power differentials between managers and employees are highlighted more in the US than in Australia). Based on these differences, it can be argued that relative to American organizations, Australian organizations would value participative decision making (lower power distance score), while at the same time, discourage risk taking (higher uncertainty avoidance score). This would explain the more participative and yet highly centralized management of the Web technologies project in our case relative to the two American cases studied by Jarvenpaa and Ives.

The importance of national culture as a determinant of diffusion process of Web technologies calls for an integration of the variable of "culture" in any model that attempts to theoretically conceptualize the process of establishing organizational web sites.

Finally, the disparity between the Jarvenpaa and Ives findings and our case can be explained by issues that are idiosyncratic to the organizations observed. This explanation calls for an in-depth analysis of the decision making patterns typical to organizations undertaking Web technologies projects, including the motivations of the various players, the politics of the process, and the influence strategies that are deemed legitimate by the organizational culture.

To conclude this discussion, we would like to present the EOWS model. Figure 1 presents a pictorial depiction of the model. As indicated in this figure, the model perceives the process of diffusion of Web technologies in organizations as a seven-step process, consisting of: Need; Conception; Investigation; Bargain; Acceptance; Delivery; and Review. The basic model in supplemented with the variables of "industry" and "culture", which are seen as modifying its basic components.

What is the meaning of the various components of the model? In the following sections, we will define and explain the content of the seven steps of the model with specific examples from Web technologies projects.

(1) Need

The Need stage is the most important step of in the EOWS process. It involves the identification of needs to be satisfied through the Web technologies project.

(2) Conception

The focus of the conception stage is on how the need, identified in the first stage should be satisfied. At the conception stage, the WWW technology is introduced and the people who are exposed to this technology consider its ability to satisfy their needs.

(3) Investigation

If the use of WWW technology is considered a means to satisfy the re-defined need, an investigation into the possibility of a wide scale diffusion will be carried out. Depending on the aforementioned factors in the Conception stage, two types of investigation can be initiated: informal investigation (not supported by top management) and formal investigation (supported and most probably resourced by top management).

(4) Bargain

The Bargain stage may take two distinct directions. First, the committee members may debate the practicability and validity of the report findings, which will eventually involve amendments to the report. Second, the committee members may debate the actual strategy of the implementation process. This could involve the sharing of responsibility for the individual components of the project, the scrambling of resources to finance the various stages of the implementation, and the fight for a better promotion of the project within the organization.

(5) Acceptance (Rejection/Re-Investigation)

The emergence of this stage concludes the process of bargaining, even though it may not reflect a state of satisfaction for all committee members. If the WWW technology is officially accepted, resources will be allocated to support its implementation. If the use of WWW technology is rejected or re-investigation is required, this will have little or no impact on the allocation of resources.

(6) Delivery

This stage is characterized by actualizing all the ideas which have been collected in the former stages and turning them into deliverables. These deliverables include the development of an organizational Web site and the production of organizational Web pages.

(7) Review

After the official launch of the organizational Web site, certain mechanisms are likely to be set up in order to encourage feedback from users internal and external to the organization. The availability of feedback mechanisms will facilitate the quality control and the inflow of new suggestions. 
Figure 1: National Culture and Industry as the Determinants of the Establishing Organizational Web Sites (EOWS) Process

Independent

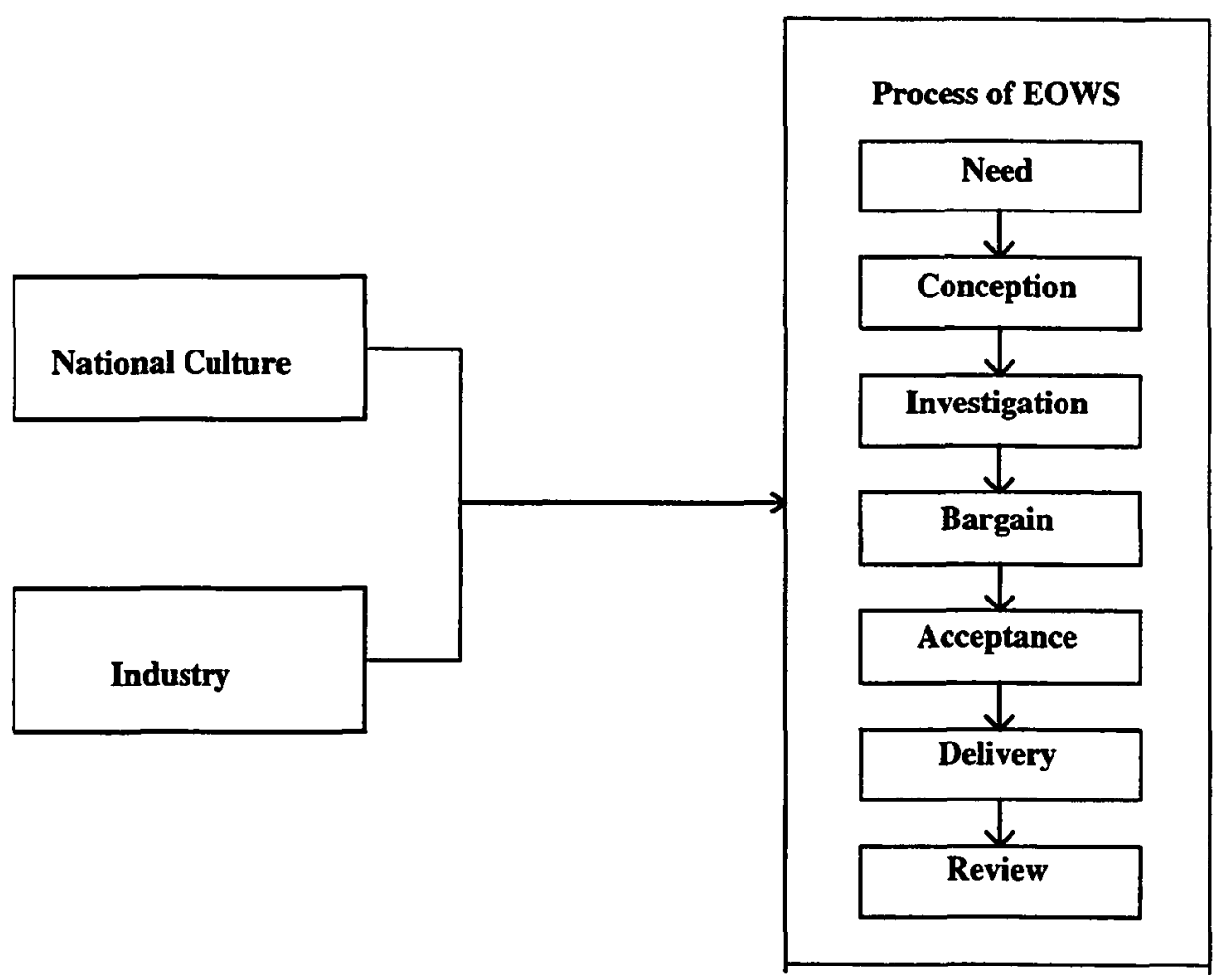

\section{CONCLUSION}

The discussion in the previous sections suggests several possible directions for future research:-

First, the seven steps in the basic model which are seen here as linear, may in some instances be circular, i.e., sub-processes that take the organization members "backward" or "forward" may occur. For example, it is possible that organizations which are at the Investigation stage may sometimes regress back to the Conception or even Need stages. It is also possible that as the process progresses new needs that have not been identified a the beginning of the process, may emerge, leading to a continual repetition of the process.

Second, the inclusion of "industry" and "culture" as variables that modify the basic seven steps of the model call for a variety of empirical investigations into the specific ways in which these variables do, indeed, modify the process. Such investigations should include in-depth studies of the process of diffusion of Web technologies in private and public sector organizations and in cultures that are not necessarily English speaking nor technologically advanced.

Finally, the EOWS model calls for an in-depth socio-political analysis of the decision making patterns typical of organizations undertaking Web technologies projects. Such analyses will involve a careful study of the power and politics of the Web technologies project, with particular emphasis on the players, their motivations, and their influence strategies.

The introduction of a Web technologies project to an organization is a far more complex process than is commonly assumed. The decision process that leads to the creation of an organization Web site involves aspects that go much beyond the technology that supports the site. The Web site is the organization's business card. It promotes the company's image externally with potential customers, competitors and partners. If the site is used as the anchor for an organizational intranet, then, it is also the carrier of the company's internal image, with its employees.

Given the key role that a Web site can play in an organization it is no wonder that the decisions that pertain to its creation and maintenance, as indicated in our case, are highly political, reflecting the interplay of different stakeholders within the organization. 
The politics of the decision making process leading to the creation of an organizational Web server or Web site is, thus, a promising area for future research. The politics of the decision making process surrounding the creation of a Web site can explain why even within the same industry and even within the same national culture (the two cases in the Jarvenpaa and Ives study) diffusion strategy can still differ markedly. When a comparison is made between organizations in different industries and cultures (our case) an understanding of the internal politics of the project can augment the explanatory power of the other two variables.

\section{REFERENCE}

Beers, M., Eisenstat, R. A., and Spector, B. (1990) "Why Change Programs Don't Produce Change", Harvard Business Review, Vol. 68, No: 6, 158-166.

Bickel, R. (1996) "Building Intranets: Internal Webs Give Companies a New Solution to an Old Problem", Internet World, 72-76.

Brown, M. and Associates (1995) Using Netscape 2, Special Edition, Que Corporation, Indianapolis.

Cash, J. I., McFarlan, F. W. and McKenney, J. L. (1983) Corporate Information Systems Management: The Issues Facing Senior Executives, Irwin, Homewood, nlinois.

Cash, J. I. and McLeod, P. L. (1985) "Managing the Introduction of Information Systems Technology in Strategically Dependent Companies", Journal of Management Information Systems, Vol: 1, No: 4, 5 23.

Dearborn, D. C. and Simon, H. A. (1958) "Selective Perceptions: A Note on the Departmental Identification of Executives", Sociometry, Vol: 21, 140-144.

Emery, V.(1996) How to Grow Your Business on the Internet, Coriolis Group, Inc., Arizona.

Gersick, C. J. G. (1991) "Revolutionary Change Theories: A Multilevel Exploration of the Punctuated Equilibrium Paradigm", Academy of Management Review, Vol: 16, No: 1, 10-36.

Hofstede, G. (1980) Culture's Consequences: International Differences in Work-Related Values, Sage Publications, California.

Hofstede, G. (1994) "Management Scientists are Human", Management Science, Vol. 40, No. 1, 4-13.

Hofstede, G. (1994) "The Business of International Business is Culture", International Business Review, Vol. 3, No. 1, 1-14.

Howell, J. M. and Higgins, C. A. (1990) "Champions of Technological Innovation", Administrative Science Quarterly, Vol. 35, No: 2, 317-341.

Jarvenpaa, S. L. and Ives, B. (1996) "Introducing Transformational Information Technologies: The Case of the World Wide Web Technology", International Journal of Electronic Commerce, Vol: 1, No: 1, 95-126.

Kalakota, R. and Whinston, A. B. (1996) Frontiers of Electronic Commerce, Addison-Wesley Publishing Company, Inc. Reading, Massachusetts.

Krol, E. (1994) The Whole Internet: User's Guide and Catalogue, 2nd Edition, O'Reilly and Associates, Inc., California.

LeJeune, U. A. and Duntemann, J. (1995) Netscape and HTML Explorer, Coriolis Group Inc., Arizona.

March, J. G. and Simon, H.(1958) Organizations, John Wiley and Sons, New York.

Markus, M. L., (1981) "Implementation Politics - Top Management Support and IS Involvement", Systems, Objectives, Solutions, 203-215.

Markus, M. L. (1983) "Power, Politics, and MIS Implementation", Communications of the ACM, Vol. 26, No: $6,430-444$.

McFarlan, F. W. and McKenney, J. L. (1982) "The Information Archipelago - Maps and Bridges", Harvard Business Review (September October), 109-119.

Pitter, K. and Minato, R. (1996) Every Student's Guide to the World Wide Web, McGraw-Hill Companies, Inc., New York.

Rayport, J. F. and Sviokla, J. J. (1995) "Exploiting the Virtual Value Chain", Harvard Business Review, Vol. 73, No: 6, 75-85.

Savola, T. Westenbroek, A. and Heck, J. (1995) Using HTML, Special Edition, Que Corporation, Indianapolis.

Schon, D. A. (1963) "Champions for Radical New Inventions", Harvard Business Review, Vol. 41, No: 2, 7786.

Sterne, J. (1995) World Wide Web Marketing: Integrating the Web into Your Marketing Strategy, John Wiley and Sons, Inc., New York. 